\title{
Students' Critical Thinking Skills in a Classroom Debate
}

\author{
Reli Handayani \\ University of Jambi \\ reli_handayani@yahoo.com
}

\begin{abstract}
Mastering argumentative discourse both in written and oral is a must for students nowadays. However, a successful argumentative discourse requires high thinking order skill such as developing a stance, analyzing arguments, distinguishing facts and opinions, solving problems, comparing and contrasting material, and making inferences. Realizing the importance roles of critical thinking in constructing argumentative discourse, this study focuses on students' performance in debate specifically argument, counter-argument, and rebuttals. They are chosen since they are always taken into consideration in assessing students' debate performance.
\end{abstract}

Keywords: critical thinking, assessment, debate

\section{Introduction}

Knowledge of the world nowadays can be obtained not only from written and oral sources, but also from the Internet. This massive information demands the students to appropriately select it based on their needs. The ability to select and analyze the relevant information is known as critical thinking. Realizing the essential role, critical thinking becomes unavoidable requirement not only in academic but also professional setting. In tertiary level of education, students are expected to develop their critical thinking skill to survive courses. In a way that critical thinking enable the students (1) to analyze, criticize, and advocate ideas,(2) to reason inductively and deductively, and (3) to reach factual or judgmental conclusions based on sound inferences drawn from unambiguous statements of knowledge or belief (Freely, 2009). Moreover, in professional setting success as an adult depend on the ability to think critically (Torr and Waburton, 2005). It is relevant in a way that critical thinking is highly correlated with some one's ability in making decisions. In short, critical thinking is an essential skill to participating effectively in communication, pursuing higher education, and succeeding in competitive world.

$$
\text { Freely (2009) explains }
$$
critical thinking as (a) life demands decision making (b) the ability to make reasoned decisions relies on critical thinking (c) skill that enables analysis and evaluation of arguments (d) skill that improves the use of information as well as advocacy. It is line with Johnson (2002) who defines critical thinking as (a) a clear, organized process involved in mental activities such as problem solving, decision making, persuading, analyzing assumptions, and scientific inquiry, (b) the ability to reason in an organized way, (c) a systematic process that enables 
students to formulate and evaluate their own beliefs and claims. Eggen (2012) offers a concise definition "critical thinking is the ability and disposition of making and doing assessment on summary based on evidence." All these definitions have the similar idea that critical thinking is the requirement of solving problem skill. Numerous definitions within the frame of critical thinking exist since it delivers different meanings for different people. Therefore, critical thinking in this study is limited to different thinking skills such as reasoning, recognizing, arguing, interpreting, summarizing etc.

In relation to the teaching method of critical thinking, a debate has been proved as an educational strategy that fosters critical reasoning and thinking skills as wall as heightens awareness of attitudes, values, and beliefs (Huber, 2006). To add, debates were incorporated in American higher educations in the $19^{\text {th }}$ through the early $20^{\text {th }}$ century, yet lost its appeal until 19880s as a teaching tool to develop critical thinking logic, and communication skill (Snider, 2006). According to Freely (2009) debate is the process of inquiry and advocacy, a way of arriving at a reasoned judgment on a proposition. Individuals may use debate to reach a decision in their own minds; alternatively, individuals or groups may use it to bring others around to their way of thinking. In relation to academic setting, Nisbett (2003) declares that debate is an important educational tool for learning analytic thinking skills and for forcing self-conscious reflection on the validity of one's ideas.
English education department in UNJA specifically speaking for professional purpose course then introduces debate as one activities of public speaking. For the purpose of this study, I utilize a prepared debate format. I select reclamation of north Jakarta beach as the issue of the debate and give them a week to prepare. I suggest them to conduct an extensive search of materials and consider some aspects of the project involving law, economic, and environmental aspect. First, researching process requires students have to skim, scan, and read related materials to expand their knowledge base. Second, analysis process covers complex activities. The students have to develop a perspective, distinguish relevant and irrelevant information, question facts and opinions, make inferences, recognize contradictions, and explore implications and consequences in order to derive in cohesive and logic arguments. Third, they are also forced to consider the opposite perspective. They have to evaluate evidence on both sides to prepare counterarguments and rebuttals. It is in line with Tumposky (2004) who argues that analysis of both sides of an argument in debate format encourages participants to step outside their personal frame of reference and become aware of their own thinking, if only to anticipate how such thinking might be vulnerable to attack from an opponent.

This insight gained throughout the pre-debate, during debate, after debate encourages the students to approach material with several sub skills of critical thinking. Peirce (2006) mentions that the 
cognitive skill dimension of critical thinking includes several skills and sub skills as follows: 1) Interpretation (categorization, decoding significance, clarifying meaning), 2) Analysis (examining ideas, identifying arguments, analyzing arguments), 3) Evaluation (assessing claims, assessing arguments), 4) Inference (querying evidence, conjecturing alternatives, drawing conclusions), 5) Explanation (stating results, justifying procedures, presenting arguments), 5) Self-regulation (self-examination, self-correction).

Realizing the importance of critical thinking, the purpose of this study is to describe how the students' critical thinking is performed in classroom debate. In other words, debate in this study is introduced as a critical thinking assessment According to Coogan and Pawson (2006) assessment should focus on various aspects such as argument and debate content, strategic presentation of arguments, verbal communication skills and argument style. Therefore, this article will focus on arguments, counterarguments, and rebuttal. First, arguments are defined as reasons given by the affirmative team to support the resolution (claim) meanwhile counter-argument are reasons given by contra team which against the resolution (claim). Second, rebuttal refers to identification of weakness in both team's arguments and ability to defend itself against attack (Latif, 2011).

\section{Research Methods}

The second semesters of students majoring in English education are the subject of this study. In the course of speaking for professional purposes, the debate is compromised of 2 teams of 4-5 students who will actually debate the issue. The members of team are assigned at random. Meanwhile affirmative and negative team is decided through lottery. After given a week for preparation, a representative from both teams will be given 5 minutes of opening speech for each. In the opening speech, they have to mention their claims and provide several arguments to support it. After that, the next 30 minutes consists of rebuttal from both teams. At the end of the debate, a representative from both teams will summarize the team's view.

The data of this study are arguments, counterarguments, and rebuttal given by both parties. Since critical thinking is an ongoing process rather than a recognizable outcome, it may difficult to measure. Thus, this study employ general education critical thinking rubric created by north-eastern Illinois University (NEIU, 2006) to analyze the data. This four-point scale rubric consists of 5 criteria relevant to critical thinking.

\section{Findings and Discussion}

Freely (2009) defines argumentation as reason giving in communicative situations by people whose purpose is the justification of acts, beliefs, attitudes, and values. Moreover, Toulmin states that people have to provide good reasons to convince other people. Good reasons may be defined as " reasons which are psychologically compelling for a 
given audience, which make further inquiry both unnecessary and redundant - hence justifying a decision to affirm or reject a proposition." The findings of this study are presented in four parts, namely arguments, counterarguments, rebuttal from affirmative team, and rebuttal from negative team.

\section{Arguments}

The first following data is the opening speech from affirmative team that consists of a claim and three arguments to support it. The arguments mentioned are positive effects of the reclamation project related to economic, geographical, and environmental aspect. The explanations given for the first and second argument demonstrate good understanding of the issue. However, the third argument can be considered as a weak argument since explanation given to support it is irrelevant with their claim, as the negative team will also object this argument later. Specifically, the third affirmative team is failed to address relationships between reclamation project and Giant Sea Wall as part of national capital integrated coastal development.

Affirmative : ... This house believe that reclamation of north beach is a good plan and should be continued. The first argument is increasing the income of Jakarta and national economies. The developer and investor will pay the tax about $15 \%$ as their contribution in investing or building factory on that land. If this reclamation succeed so Jakarta will be one of the forward city in the world that attract the tourists. The second argument is expanding the area of Jakarta's mainland. Jakarta's population is increasing every year, but the land is limited. That land can be filled with building that can be enabled for residential, office or other activities. The third argument is it can decreasing the flood. Jakarta must build giant dike (Giant Sea Wall) to prevent flooding because the soil every year in Jakarta fell by $15 \mathrm{~cm}$, if not immediately addressed it floods every year gets worse. So that's all our arguments, thank you.

\section{Counter-argument}

The opening speech from negative team is called counterargument for it against affirmative team's claim. If the affirmative team comes up with three arguments, negative team then provides five counter-arguments to support their claim. They build their first and second argument based on their concern of negative environmental effects. Yet, both arguments have a similar idea that is "causing environmental problem" without mention specific detail for each. Related to critical thinking, they are not successfully labels dimension of the problem. Moreover, the use of "high possibility" in first argument shows that they identifies important assumptions, but do not evaluate them for clarity. The economical aspect for local fishermen and upper class people is mentioned in third and fifth arguments. However, the last argument is inappropriate since it is built on assumption instead of fact. To add, the fourth argument is under developed from the aspect of completeness because it is lack of explanation. 
Negative : ... i want to explain eh.. the problem with thing about the land reclamation project. There are 5 points from us. First. As the project builds at least 17 artificial islands with a projected total area as big as bogor. It will significantly outer and be grade be already fragile environment of costal jakarta. There is high possibility that the land reclamation does not help jakarta subsidence problem and that it and than that it will even weed to other environmental problems. Second the presence of artificial island will changes the sea current with which can lead to the erosion of near bay natural island or worsen including out of the city. Third. The project will affect... will affect fisherman. Because they will have to go farther out to sea. Increasing their gasoline expenses. Fourth, the project also clash with other construction project and existing infrastructure. Fifth, there also possibility that the land will mainly be use by higher income citizen instead of benefit in the public at large, the reason glave clash reflect the tendency of developers to exploit land and private benefit instead of the public. Thank you.

The following data shows another counter-argument concerning with legal aspect of the reclamation project. The negative team develop well elaborated counter argument completed with accurate evidence. Here, the skill of evaluating evidence shows high proficiency since they not only identify important evidence but also provide it as information for consideration.

Negative: well. I want to bring out the legal basis of this project. The jakarta governor Mr. ahok always use presidential decree number 52 from 1995 but since presidential degree number 54 from 2008 came out. It's one of the point this president decree number 50 from 1995 is expired and cant be use again anymore as legal basis. so $\mathrm{i}$ said this project illegal because doesn't have any legal basis

\section{Rebuttal}

In contrast to arguments, rebuttals are used to disprove the validity of argument or claim. Thus, good rebuttals generally have a basic statement, explanation, analysis and supporting evidences. Both affirmative and negative teams have to raise objection in order to show argument's weakness of the opposite team. Another function of rebuttal is to defend from opponent's attack. The data below is started with counter argument saying "reclamation can increase environmental problem" and followed by each team rebuttals.

Affirmative: And I also disagree with your argument, the first argument, that the reclamation can increase the environmental problem. It can increase it, the environmental problem. Let you know the fact is the reclamation can also provide a positive impact to wildlife and can anticipate climate change and habitat. So it's for public, it's not only for rich people, it's for environmental. (rebuttal)

Negative: well Iam really I strong disagree with you. Because eee actually ee the environmental impacts from these land reclamation eee.. it's from the environmentalist said that ee.. great such as great 
garuda wall a separate but related project it will be more even restive because eehm taslim arifin a researcher at the research and development center from marine and coastal resources and the ministry said that the water inside great garuda wall would also become a problem as the water trap the pollutantss deposit by 13 river in jakarta would accumulate in one place the water inside the sea would become a big pound of polution. So I think the environment... the environmental problem just will be getting be more worst not even better. (rebuttal)

Affirmative: No, you are wrong, you know the reclamation of Indonesia will seems like the Singapore's reclamation, and you know in Semakau Landfill, Singapore, the reclamation of land used as sewage treatment. In addition, this area is also used as the conservation of flora and fauna. And this area is also used as a recreational area, and it's very useful because we can get more tax (income) from the recreational and then it can get more tourist to come to our country, and Basically, the reclaimed areas generally can be more secure against erosion, it's the point, it can make secure against the erosion, this is because the construction of the security is set up as hard as possible to be able to withstand the onslaught of the waves of the sea. Another benefit is, the reclamation can restore the affected coastal abrasion configuration to its original shape, so it's very useful. (rebuttal)

The counter-argument saying that reclamation project may harm the environment is rebutted by affirmative team. However, the negative team respond and dealt it effectively by including expert's opinion "Taslim Arifin." The debate becomes more interesting when the affirmative team also gives example of Singapore's reclamation success. Both teams success in identify important evidence and using it to defend their claims constitutes critical thinking.

\section{Rebuttal from Affirmative Team}

The first rebuttal is stated by the affirmative team in order to against the fifth argument purposed by negative team. From the structure, it is considered as effective rebuttal since they state the argument that is going to be refuted, disagreement expression, reason of disagreement, and conclusion. They realize that the statement given by negative team is assumption that is not supported with adequate evidence.

Negative : .... There also possibility that the land will mainly be use by higher income citizen instead of benefit in the public at large, the reason glave clash reflect the tendency of developers to exploit land and private benefit instead of the public. (claim)

Affrmative : I want to ask you what that you said before, the reclamation can will only use by the rich people and the poor people can't enjoy that, it's like, I don't think so because with the reclamation the poor people they can get any, they can get the jobs from there, of course from the first they build the reclamation of course they need the worker and worker so they can work that and if the building is done, they need employee just like so they can, so it 
can open the new job vacancy so I don't think that only the rich people can use that and for the government that they in the reclamation place plan it will save any public place facility not only for the rich people but the poor people who take any advantages from the land reclamation. (rebuttal)

During the debate, several poor rebuttals related to counterargument of illegal base for the reclamation project occur. The underlined utterances show that rebuttal is built of personal opinion. Responding to the first rebuttal, the negative team acknowledge objections from affirmative team and provide convincing replies to these. They also restate its component propositions and reconstructs their relationship correctly. Dealing with second rebuttal, the negative team succeed defending its' counterargument by stating fact as written in bold.

Affirmative: okay and I want to answer Chris's argument that you said the president decision is not valid, and how can you said like that but the law is still valid until now from what we read before. If not we believe the reclamation is can't continue until now, if illegal it is not continue. (rebuttal)

Negative: wait I want to explain to you. first the presidental degree number 54 from 2015 from 1990 is especially made for this reclamation project. And one that my favorite is for if they want to make the reclamation project. this is if if you want to make the reclamation project you use this but this one is made by president soeharto especially for this program but in 2008 the presidential degree is expired and this one ahok doesn't know. that's why you know the main reason is the project is been stop because it doesn't have any legal basis. Ahok say yes he doesn't know that before so that's why they still made law for it

Affirmative :How can you said that Ahok didn't know that laws is not valid again or it's expired, you know Ahok is a president of Jakarta, so of course he really knows that the president decision is still valid until now. (rebuttal)

Negative : ahok admit him self he does not know. that's why the project been stop the main reason this project because it doesn't have any legal basis.

\section{Rebuttal from Negative Team}

The first rebuttal from negative team is aimed to object the third argument from affirmative team. The negative team realize that there is no logical relation among its proposition in the affirmative team's argument. Their rebuttal is constructed clearly by using causal effect relation.

Affirmative : ...the third argument is it can decreasing the flood. Jakarta must build giant dike (Giant Sea Wall) to prevent flooding because the soil every year in Jakarta fell by $15 \mathrm{~cm}$, if not immediately addressed it floods every year gets worse. (claim)

Negative : ... You said that eee this aa jakarta this land reclamation would decrease flood in jakarta city. I dont think so. Because aaa emm the.. the land reclamation ee... just will worsen flooding of the city. because ee the..the sea current is traped ee by the artificial island so it 
would a fact and to worsen the flood in city. Not decreasing it (rebuttal).

On the contrary, the following data exemplify poor rebuttal. The use of "if you watch," you can see the news,' three times occurrences of 'we can smell' are linguistic evidence of personal opinion. In relation to critical thinking, the rebuttal shows that they identifies embedded issues but do not explain its relation to counterargument or how and why it become problem. In the end, it derives them into inaccurate conclusion.

AG : ...so I don't think that only the rich people can use that and for the government that they in the reclamation place plan it will save any public place facility not only for the rich people but the poor people who take any advantages from the land reclamation. (claim)

NG : : ehm i think..ehm i want to say that aaa $\mathrm{i}$ really aaa disagree with you. Well,there is.. if you watch news these days. The reason keys a reflect the tendency of developers to exploit land for private benefit, instead of the public. Because aaaa and that's from emmm that case, we can eeehm we can smell something fishy that in future eee the land actually will just benefit the higher income citizen not...not everyone, not not the public. We can smell it just from this case. You can see the news that the developers drive the government. From that case you can smell that actually there is something fishy behind it. Why they want to exploit the land from for themselves. It means that they.. They not actually build this for public benefit but just for their themselves benefit. and I think so. That's the proof. (rebuttal)

\section{Conclusion and Suggestion}

The finding of the study demonstrate that debate enhance not only students' communication skill but also their critical thinking skill. Debate enables students to present their understanding of a topic, questioning others' opinion, arguing others' argument, reasoning and clarifying their argument, and evaluate others. Regarding to the finding of the study, there are some suggestions that can be proposed. First, the students have to practice to construct a coherent and logic argument. They also have to control their emotions when the debate is getting heated. Second, the teachers or lecturers have to arrange format of debate based on students' needs, number, and competence. As a challenge, the debate can be conducted in sudden so they are forced to think critical on the spot. Third, the future researcher may employ other standardized critical thinking assessment tools or even develop it themselves.

\section{References}

Coogan, J. and Pawson, C. (2006) "Widening Participation and Debate in Psychology", Psychology Learning and Teaching Conference, 27 - 29 June, York St John University College, York.

Eggen, P and Kauchak, D. (2012). Strategies and Models for Teachers: Teaching Content and Thinking Skills. USA: Pearson Education, inc.

Freely, A. J. (2009). Argumentative and Debate. California: Wadsworth Co. 
Halonen, J.S. and Gray, C. (2001). Critical Thinking Companion: For Introductory Psychology, Worth Publishers Inc

Huber R and Snider A.C. Influencing through Argument. Updated ed. New York: International Debate Education Association; 2006

Johnson, E. (2002). Contextual Teaching and Learning: Menjadikan Kegiatan Belajar-Mengajar Mengasyikkan dan Bermakna, (Indonesian translation). Bandung: MLC.

Latif, M.A. (2011). A Comprehensive Guide to Debate Adjudication. Retrieved August $2^{\text {nd }} 2016$, from http://www.debatepedia.idebate.org/en/index.php.

NEIU. (2008). Northeastern Illinois University General Education Critical Thinking Rubric. Retrieved August $2^{\text {nd }}$ 2016, from http://www.neiu.edu/ neassess/gened.htm\#rubric

Nisbett, R. E. (2003) The Geography of Thought. The Free Press.

Peirce, W. (2006). Designing Rubric for Assessing Higher Order Thinking. Retrieved August $\quad 2^{\text {nd }}, \quad 2016, \quad$ from http://www.academic.pg.cc.md.us/ wpeirce.html

Snider A, Schnure M. (2006). Many Sides: Debate Across the Curriculum. New York: International Debate Education Association.

Tumposky, N. (2004). The Debate Debate. The Clearing House, 78: 42-55. 